\title{
O CÍRCULO DE ESTUDOS BANDEIRANTES
}

\author{
Kátia Maria Biesek ${ }^{1}$ \\ Luciano Chinda Doarte ${ }^{2}$
}

- Enviado em 08/08/2015

- Aprovado em 18/08/2015

O Círculo de Estudos Bandeirantes foi fundado em 1929 por um grupo que idealizava formar a intelectualidade católica de Curitiba. De acordo com Liguaru Espírito Santo, que fez parte da segunda onda de fundadores da Entidade, os primeiros entusiastas eram:

[...] um sacerdote inteligentíssimo, recém-chegado do Velho Mundo [...], Pe. Luiz Gonzaga Miele; o segundo, um jovem e estudioso médico recém-formado no Rio de Janeiro, [...] José Loureiro Ascenção Fernandes; o terceiro, ainda acadêmico da Faculdade de Direito da nossa Universidade [UFPR], José Farani Mansur Guérios, [...]. Aos três unia - cor unum et anima uma - como um só coração e uma só alma, o sacrossanto liame da Fé. Fé no mesmo Deus de nossos altares; Fé no Bem e no Justo, Fé na Civilização e na Cultura. ${ }^{3}$

Ainda de acordo com Santo, depois dos pioneiros somaram-se Antônio Rodrigues de Paula, Benedicto Nicolau dos Santos, Bento Munhoz da Rocha Netto, Carlos de Araújo Brito Pereira, José de Sá Nunes, Pedro Ribeiro Macedo da Costa e Valdemiro Augusto Teixeira de Freitas, totalizando onze fundadores.

\footnotetext{
${ }^{1}$ Graduada em Secretariado Executivo (1988), especialista em Didática do Ensino Superior (1994) e Mestre em Educação (2003) pela Pontifícia Universidade Católica do Paraná. Atualmente atua como Coordenadora do Círculo de Estudos Bandeirantes e do Centro de Memória da PUCPR. Endereço eletrônico: katia.biesek@pucpr.br.

${ }^{2}$ Titulado em Conservação-Restauração pelo Ministério da Cultura (2013). Formado no curso de Gestion de Patrimoine et Collections da École du Louvre (2015). Graduado em História pela Pontifícia Universidade Católica do Paraná (2015). Especializando em História da Arte pelo Centro Universitário Claretiano. Atualmente faz parte do corpo técnico do Círculo de Estudos Bandeirantes e do Centro de Memória da PUCPR. Endereço eletrônico: lucianochinda.lcd@gmail.com.
}

${ }^{3}$ REVISTA DO CÍRCULO DE ESTUDOS BANDEIRANTES. Edição Especial comemorativa do $25^{\circ}$ aniversário de fundação do Círculo de Estudos Bandeirantes. Curitiba: Papelaria Requião, tomo II, set. 1954. p. 747. 
Os encontros com o intuito de fundação do CEB começaram em março de 1929 e, após várias reuniões e inscrições de associados, em setembro do mesmo ano, foi oficialmente instalada a entidade. E como nos diz José Loureiro Ascenção Fernandes, os trabalhos começaram logo depois da fundação:

Semanalmente, aqui nos reuníamos para assentar as bases do edifício que projetávamos erguer. Aventávamos idéias, discutíamos alvitres, tomávamos as providências julgadas oportunas, organizávamos os estatutos, determinávamos, enfim, o que melhor se nos antolhava para garantir o êxito do Círculo de Estudos. ${ }^{4}$

Entretanto, mesmo sendo fundada a instituição, a sede própria ainda não existia, por isso, por quase uma década, o CEB funcionou no porão da casa do casal Manoel Ascenção Fernandes e Julieta Fernandes, pais de José Loureiro. E por ocuparem um lugar subterrâneo, o Pe. Luiz Gonzaga Miele dizia que seus colegas ocupavam as "formosas catacumbas", e o Padre repetiu a nomenclatura em diversas cartas trocadas com os colegas enquanto estava em São Paulo.

Durante muito tempo a Diretoria do Círculo tentou, junto ao governo municipal de Curitiba e do Estado do Paraná, conseguir um terreno para construir sede própria. Os trâmites se iniciaram em 1938, quando uma Comissão do Círculo se reuniu com o então Prefeito Dr. Alexandre Gutierrez Beltrão, e este informou que o terreno cobiçado pelos intelectuais estava prestes a passar para o poder do Governo do Paranás. Durante os anos de 1940 e 1941 foram feitas reuniões e enviados pedidos, até que o Poder Público Estadual concorda em fazer a doação do terreno sito à Rua XV de Novembro. A Presidência da República, na pessoa do Interventor Federal Manoel Ribas, lavrou a lei que livrara de impostos a Entidade, em $1942^{6}$.

Como a instituição não dispunha de fundos numerários para a construção do prédio, foram estabelecidas duas modalidades de arrecadação do capital necessário. A primeira destinava-se aos sócios do CEB, os quais podiam voluntariamente doar mensalmente a quantia de vinte e cinco mil réis, e fariam parte dos "Bandeirantes-Construtores". A segunda se dava através do "Livro de Ouro", pelo qual não só sócios, mas também alheios ao Círculo, poderia doar qualquer valor para ajudar na arrecadação ${ }^{7}$. Após avaliarem muitos projetos, João de Mio foi o arquiteto escolhido, o prédio foi construído e inaugurado em 1945.

\footnotetext{
${ }^{4}$ ARQUIVO do Círculo de Estudos Bandeirantes. Relatório de 1929-1931.

${ }^{5}$ CÍRCULO DE ESTUDOS BANDEIRANTES. Livro de Atas n. 1, fl. 65.

${ }^{6}$ ARQUIVO do Círculo de Estudos Bandeirantes. Relatório de 2 jul. 1942. Relatório de 2 jul. 1942.
} 
Durante sua história, o CEB foi mantido por iniciativa privada, estadual, até que em 1987 os Irmãos Maristas tomaram posse dele, colocando-o como parte da Pontifícia Universidade Católica do Paraná, já que a Universidade teve seu início na Faculdade de Filosofia, Ciências e Letras, fundada no próprio Círculo.

O acervo do Círculo começou a se formar aos poucos, como qualquer entidade cultural. Um grande volume de material inaugurou os trabalhos de se guardar coleções no CEB. Este material eram os livros contábeis manuscritos da "Casa Comercial Fernandes Loureiro", que retratam o histórico do comércio feito com carroças no Paraná, assim como as estradas comerciais mais usadas, entre outros aspectos históricos, e comportam o período de 1881 até 1900. Além de documentos históricos, o acervo foi e vem sendo composto de bibliotecas, sendo mais conhecida e frequentada a sessão paranaense. $\mathrm{O}$ acervo bibliográfico também é formado por obras de História Geral, Legislações Históricas, Geografia, Biografia, Literatura, Antropologia, e demais temáticas comportadas pelos estudos da cultura.

Desde de 2013, o acervo do Círculo de Estudos Bandeirantes está ligado ao Curso de História da PUCPR, e vem sofrendo uma reformulação em seus trabalhos e objetivos. Atualmente é desenvolvido um trabalho mais criterioso com o acervo. Foi fundada uma Comissão de Acervo ${ }^{8}$, que tem como foco julgar o que deve compor as coleções do CEB. Também está se promovendo um tratamento adequado de Higienização, Conservação, Restauração e Acondicionamento para os materiais, e segue-se como modelos de trabalho instituições renomadas com muito tempo de atividades na área como a Biblioteca Nacional.

O acervo é composto por fotografias, documentos, livros, objetos tridimensionais, dissertações, teses, obras de arte etc. e entre as coleções, estão a "José Loureiro", antropólogo, professor e fundador do CEB, sua coleção é a mais volumosa, conhecida e pesquisada e é composta por fotografias, relatórios de trabalhos de campo, planejamentos de aula, croquis de aldeias indígenas, desenhos de próprio punho de armadilhas e demais objetos das tribos que estudava, etc.; "Bento Munhoz da Rocha Netto", político e fundador do CEB, a sua coleção guardada representa-se nos recortes de jornais, que fez durante muitos anos de sua vida, com diversas temáticas; "Clemente Ivo Juliatto", reitor da PUCPR, do qual o Centro de Memória da PUCPR, lotado no CEB, guarda toda sua biblioteca, além de condecorações e outros objetos pessoais; "Periódicos", com títulos históricos variados como Ilustração Brasileira (séc. XIX e XX) e Veja Paraná; "Mapas”, com levantamentos territoriais do Paraná, como as glebas da Serra dos Dourados; "Sebastião Ferrarini”, historiador e professor que dedicou trinta anos de trabalho ao CEB e continuou o trabalho dos 
fundadores preservando o acervo histórico; entre outras. A realocação da biblioteca, também um projeto novo, deixará mais fácil o acesso de pesquisadores e estudantes, além de oferecer um espaço para estudos.

Além do acervo próprio, pode-se encontrar no Círculo de Estudos Bandeirantes o acervo do Centro de Memória da PUCPR, que detém documentos (ofícios, memorandos etc.), fotografias, objetos (condecorações, presentes etc.) e livros (atas, registros de notas, diários de classe etc.) que contam a história da Universidade, desde a Faculdade de Filosofia, Ciências e Letras até a atualidade.

Outra atividade do Círculo é o cineclube, chamado Cine Círculo, que, através de uma programação mensal, tem o intuito de valorizar o cinema nacional e estadual através de debates, exibições, oficinas, capacitações e outras atividades. Como projetos futuros, estão a criação de um setor de Ação Educativa, que deve oportunizar a disseminação do conhecimento com visitas guiadas e estudos dirigidos; e um setor de Educação, que deve promover grupos de estudos, cursos e afins, com o intuito de discutir, disseminar e produzir novos conhecimentos nas diversas áreas da cultura.

O Círculo sempre foi o que continua a ser no presente. Um organismo agregador de talentos, de intelectuais, de pessoas preocupadas com a cultura e um valioso instrumento divulgador da cultura paranaense.

ENDEREÇO: Rua XV de Novembro, 1050 - Centro - Curitiba/PR

CONTATO: (41) 3222-5193 / circulo.bandeirantes@ pucpr.br

HORÁRIO DE FUCIONAMENTO: de segunda à sexta - das 09h00 às 17h00

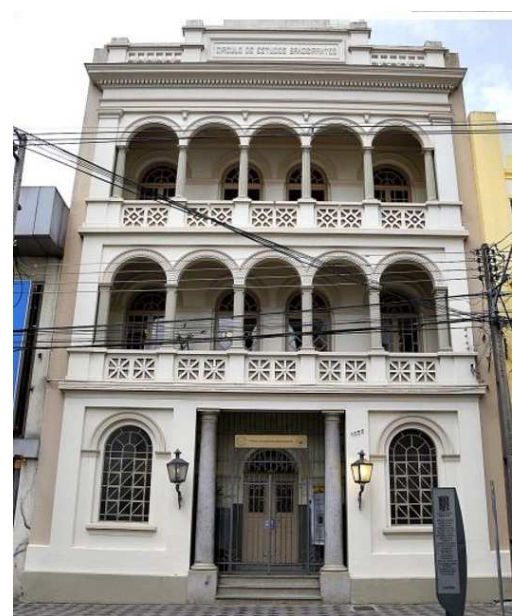

Foto acervo Círculo de Estudos Bandeirantes 